\title{
HERV-K18 Env Expression and the Potential Association With TGF- $\beta$ and Epstein-Barr Virus Infection in the Presence and the Absence of Vitamin D in Multiple Sclerosis Patients
}

\section{Tayebeh Latifi}

Tehran University of Medical Sciences

Majid Teymoori-Rad

Tehran University of Medical Sciences

Ahmad Nejati

Tehran University of Medical Sciences

Shohreh Shahmahmoodi

Tehran University of Medical Sciences

\section{Farhad Rezaei}

Tehran University of Medical Sciences

Sayed Mahdi Marashi ( $\sim$ m-marashi@tums.ac.ir)

Tehran University of Medical Sciences https://orcid.org/0000-0001-7754-2674

\section{Research Article}

Keywords: Human endogenous retroviruses, Multiple Sclerosis, HERV-K18 env, Transforming growth factor beta, Epstein-Barr virus, Vitamin D

Posted Date: July 26th, 2021

DOl: https://doi.org/10.21203/rs.3.rs-725905/v1

License: (c) (i) This work is licensed under a Creative Commons Attribution 4.0 International License. Read Full License 


\section{Abstract}

Previous studies have reported that Human endogenous retroviruses (HERVs) such as HERV-K18 is associated with an increased risk of multiple sclerosis (MS). The present study aimed to evaluate the association between the expression of HERV-K18 env, TGF- $\beta$, and in vitro effect of EBV infection on the expression level of HERV-K18 env in PBMC of MS patients in both presence and absence of vitamin D (1,25-OHD). The levels of HERV-K18 env was measured in peripheral blood mononuclear cells (PBMCs) from 20 MS patients and 20 healthy controls by quantitative real-time PCR. PBMCs were further treated with EBV in the presence or the absence of vitamin D. After 72 hours, cells were collected for measurement of HERV-K18 env expression using Real-time PCR. While the expression of HERV-K18 env was significantly higher in MS patients than healthy controls, the expression of TGF- $\beta$ was found to be significantly lower in MS patients compare to healthy controls. Interestingly, an inverse correlation was found between HERV-K18 env expression and TGF- $\beta$ expression in MS patients but not for healthy controls. Although in vitro stimulated PBMCs with EBV showed no significant differences in terms of HERV-K18 expression, EBV infected cells revealed different patterns in the presence and the absence of vitamin D treatment. These findings not only support the important role of HERV-K18 env expression but also highlight the plausible interactions with different risk factors in MS.

\section{Introduction}

Multiple sclerosis (MS) is a chronic inflammatory disease of the central nervous system (CNS) that occurs mainly in young adults aged 20-40 years [1]. While both genetic and environmental factors are attributed as risk factors for MS development [2], it is largely unclear how different risk factors act in this scenario [3]. The interplay between different environmental risk factors particularly Epstein-Barr virus (EBV) infection, vitamin D deficiency, and human endogenous retroviruses (HERVs) have recently gained much attention in the field of autoimmune diseases $[3,4]$. The plausible interaction between EBV infection and vitamin D status has been previously highlighted $[5,6]$. Indeed, increased anti-EBNA-1 IgG antibodies and reduced 25(OH)D levels have been described prior to the first clinical manifestation of MS [7]. Furthermore, a seasonal fluctuation has been observed between anti-EBNA-1 IgG levels and 25(OH) D levels in relapsing remitting MS (RRMS) patients [8].

HERVs are a family of ancient viruses, which consist around $8 \%$ of our genome $[9,10]$. While their existence has been known for years, the biological implications of HERVs in different settings including MS have recently gained more attention [11]. Certain HERV families including MRSV/HERV-W, HERV-H, and HERV-K have been reported to play an important role in MS although it is largely unclear if these risk factors act independently or jointly [12-15]. It has been previously described that EBV infection can transactivate the expression of HERV-K18 env gene [16, 17], which has a superantigen activity with strong capability of stimulating $T$ cells [18].

While the plausible interaction of viral infections particularly EBV and HERVs has been well arknnumbernod in tho fiold of autnimmuno dicoscoc innlunfing MS [19], less data are available with regards Loading [MathJax]/jax/output/CommonHTML/fonts/TeX/fontdata.js 
to HERVs and vitamin D status. In line with our previous findings, the present study aimed to first evaluate of HERV-K18 env, TGF- $\beta$ and then further delineate the in vitro effects of EBV infection on the expression levels of HERV-K18 env and TGF- $\beta$ in PBMCs of MS patients and healthy controls in the presence and the absence of 1,25-OHD.

\section{Methods And Martials:}

Study population. Twenty MS patients ( 15 females and 5 males; mean age $35 \pm 5$ years) and 20 healthy control subjects ( 15 females and 5 males; mean age $34.1 \pm 5$ years) were recruited. All MS patients had been diagnosed based on McDonald's criteria [20] and assessed for clinical picture (Expanded Disability Status Scale: EDSS) by clinicians at the MS Research Centre, Sina Hospital, Tehran, Iran. All study participants gave informed consent to provide $10 \mathrm{ml}$ blood samples for the study, which was approved by the local research ethics committee (approval code: IR.TUMS.SPH.REC.1395.756) of Tehran University of Medical Sciences (TUMS).

Sample Preparation. Peripheral blood mononuclear cells (PBMCs) were separated from fresh whole blood by Ficoll- Paque centrifugation (GE Healthcare Life Sciences, Massachusetts, USA), resuspended in RPMI 1640 (Gibco Life Technologies, USA) supplemented with 10 \% FCS (Gibco), and used fresh.

EBV and vitamin D preparation. EBV stock was prepared as described previously [21]. Briefly, B95-8 cells were grown $3-4$ weeks at $37^{\circ} \mathrm{C}$ with $5 \% \mathrm{CO} 2$ in RPMI- 1640 supplemented with $10 \% \mathrm{FCS}$, penicillin (100 IU) and streptomycin (100 lg/ml) (Biosera, Ringmer, East Sussex, UK) as completed medium 10\% (CM10). After removal of remained cells and debris by centrifugation at $600 \mathrm{~g}$ for $6 \mathrm{~min}$ at $4^{\circ} \mathrm{C}$, the supernatants were passed through a $0.45 \mu \mathrm{m}$ membrane filter (Millipore, Billerica, USA) and concentrated by Beckman ultracentrifuge (L8-80 M; Beckmann, Palo Alto, CA,USA) at 30,000 g for two hours at $4{ }^{\circ} \mathrm{C}$. The pellets containing concentrated virus were re-suspended with $\mathrm{CM}-10$ in 1/100 of original volume, passed through a $0.22 \mu \mathrm{m}$ filter, aliquoted and stored in cryovials at $-80^{\circ} \mathrm{C}$.

As described previously [22] the infectious capability and the absolute amount of EBV genome was determined. To optimize the virus concentration, PBMCs (with $1 \mu \mathrm{g} / \mathrm{ml}$ cyclosporine) and B cells were transformed by different titers of virus and $15 \times 10^{6}$ copies included further in all experiments to minimize inter-assay variations. To determine the optimal vitamin D concentration, the expression of VDR and CYP24A1 was checked after PBMCs treatment with different concentration of vitamin D and $100 \mathrm{nM}$ of vitamin D showed the best expression of VDR and CYP24A1.

EBV stimulation in the absence and the presence of vitamin D. PBMCs were infected with EBV and seeded into 24 -well plates $\left(1 \times 10^{6}\right.$ cells/well) (SPL Life Science Co, Phcheon-si, Gyeonggi-do, Korea) and incubated at $37^{\circ} \mathrm{C}$ in a $5 \% \mathrm{CO} 2$ atmosphere in the presence and the absence of $100 \mathrm{nM}$ recombinant 1,25-(OH)2D (Enzo Life Sciences, Inc., AnnArbor, MI.). After 72 hours, supernatants and cells were collected and stored at $-80^{\circ} \mathrm{C}$ until further use. Our previous study [22] showed 72 hours' post-infection was considered as optimal time for cells harvestina for the both EBV activity and vitamin D metabolism. Loading [MathJax]/jax/output/CommonHTML/fonts/TeX/fontdata.js 
RNA extraction and cDNA synthesis. RNA from PBMCs (both treated and untreated cells) were manually extracted by Trizol according to the manufacturer's instructions (Roche, Mannheim, Germany). The final RNA pellet were dissolved in $30 \mu$ of RNase and DNase water (Invitrogen). The purity and concentration of total RNA were determined using a Nano Drop ND-1000 (Thermo Fisher Scientific, Wilmington, DE, USA). $1000 \mathrm{ng}$ of total RNA was used for CDNA synthesis according to the manufacturer's instructions (Roche, Mannheim, Germany).

Determination of HERV-K18 env and TGF $-\beta$ and level in PBMCs. Relative quantitative (RQ) RT-PCR was applied to quantify the expression of HERV-K18 env (before and after treated) and TGF- $\beta$ by using SYBR ${ }^{\circledR}$ GreenER ${ }^{T M}$ qPCR SuperMix Universal (Roche, Mannheim, Germany) on the on the Rotor-Gene ${ }^{\circledR}$ 6000 (Corbett Research, Sydney, Australia). PCR amplification reactions were performed in $25 \mu$ reaction mixtures containing CDNA (1:10 fold diluted), $12 \mu \mathrm{l}$ SYBR Green, and $10 \mathrm{pmol}$ of each primer. The reactions were incubated at $95^{\circ} \mathrm{C}$ for $10 \mathrm{~min}$, followed by of $95^{\circ} \mathrm{C}$ for $15 \mathrm{~s}, 57^{\circ} \mathrm{C}$ for $30 \mathrm{~s}$, and $70^{\circ} \mathrm{C}$ for 30 s. A melting curve analysis was performed to confirm single gene-specific peaks. The linearity and accuracy of real-time RT-PCR were evaluated using glyceraldehyde-3-phosphate dehydrogenase (GAPDH), as a reference gene, and standard curve derived from amplifying serially diluted pooled cDNA. Biomarker expression patterns were analyzed according to the $2^{-\Delta C t}$ method [23]. The relative values of each biomarker were expressed as change fold to compare mRNA levels between treatment groups.

Statistical analysis. GraphPad Prism software, version 8 (GraphPad software, Inc, La Jolla, California) was used for plotting graphs and statistical analysis. $p$ values $\leq 0.05$ were regarded as significant. Data are presented either with median or mean \pm SEM.

\section{Results:}

Demographic characteristics. Twenty MS patients with different forms of disease including RRMS $(n=9)$, SPMS $(n=5)$, and PPMS $(n=6)$ were included for the purpose of this study. Demographic and clinical features of MS patients are summarized in Table 1. As controls, 20 age and sex matched healthy subjects were also included in this study. All patients received treatment except 3 , which considered as 'drug naïve'. Among patients 7 have received rituximab and the rest received Tysabri, Dalfira, and Fingolimod either alone or in combination. All patients in this study were non-smokers and, except 3 , all received different doses of 25 -hydroxy-vitamin D supplements. 
Table 1

Demographic and clinical characteristics of MS patients.

\begin{tabular}{|c|c|c|c|c|c|c|}
\hline ID & Type & EDSS score & Age (years) & Sex & Vitamin D supplement & Treatment \\
\hline MS1 & RRMS & 0 & 23 & $\mathrm{~F}$ & No & Drug naïve \\
\hline MS2 & RRMS & 1 & 38 & M & 5000U/10day & Drug naïve \\
\hline MS3 & PPMS & 6.5 & 33 & $\mathrm{~F}$ & 5000/2week & Rituximab/Dalfira \\
\hline MS4 & RRMS & 1.5 & 28 & $\mathrm{~F}$ & 5000/month & Tysabri \\
\hline MS5 & SPMS & 6.5 & 44 & $\mathrm{~F}$ & 5000/2week & Rituximab \\
\hline MS6 & PPMS & 6.5 & 41 & $\mathrm{~F}$ & 5000/2week & Dalfira/Bioten \\
\hline MS7 & SPMS & 5 & 34 & $\mathrm{~F}$ & 5000/2week & Tysabri \\
\hline MS8 & PPMS & 6.5 & 41 & M & No & Rituximab \\
\hline MS9 & PPMS & 6 & 34 & $\mathrm{~F}$ & 5000/2week & Rituximab \\
\hline MS10 & PPMS & 6 & 34 & M & 5000/2week & Rituximab \\
\hline MS11 & SPMS & 4.5 & 38 & $\mathrm{~F}$ & 5000/2week & Rituximab/Dalfira \\
\hline MS12 & RRMS & 1 & 34 & $\mathrm{~F}$ & No & Recigene \\
\hline MS13 & RRMS & 3 & 31 & $\mathrm{~F}$ & 5000/2week & Tysabri \\
\hline MS14 & SPMS & 6 & 33 & $\mathrm{~F}$ & 4000/day & Rituximab \\
\hline MS15 & RRMS & 1 & 40 & $\mathrm{~F}$ & 5000/2week & Fingolimod \\
\hline MS16 & RRMS & 1 & 40 & $\mathrm{~F}$ & 5000/2week & Fingolimod \\
\hline MS17 & RRMS & 1 & 38 & $M$ & 50000/10Day & Recigene \\
\hline MS18 & SPMS & 6 & 33 & $\mathrm{~F}$ & 4000/Day & Rituximab \\
\hline MS19 & RRMS & 0 & 23 & $\mathrm{~F}$ & No & Drug naive \\
\hline MS20 & RRMS & 6 & 40 & M & 5000/2week & Fingolimod \\
\hline \multicolumn{7}{|c|}{$\begin{array}{l}\text { RRMS (Relapsing Remitting MS), PPMS (Primary Progressive MS), SPMS } \\
\text { (Secondary Progressive MS) }\end{array}$} \\
\hline \multicolumn{7}{|c|}{ F: Female, M: Male } \\
\hline \multicolumn{7}{|c|}{ EDSS: Expanded Disability Status Scale } \\
\hline
\end{tabular}

HERV-K18 env expression on PBMCs. To ascertain the expression of HERV-K18 env in MS, we assessed HERV-K18 env expression in PBMCs taken from MS patients and healthy individuals, as control group. The expression level of HERV-K18 env was found to be significantly higher in MS patients compared to Loading [MathJax]/jax/output/CommonHTML/fonts/TeX/fontdata.js ceived rituximab, data were further analyzed 
based on rituximab treatment. As shown in Fig. 1B, MS patients with no rituximab showed significantly higher levels of HERV-K18 env when compared to healthy controls $(p=0.01)$ but not with those who received rituximab $(p>0.05)$.

We further aimed to check whether there is correlation between HERV-K18 env and MS disease severity. As indicated in Figs. 1C and 1D, no significant differences were found when data obtained from HERVK18 env analyzed based on either EDSS score or MS forms ( $p>0.05)$.

TGF- $\beta$ expression on PBMCs. Given the importance of TGF- $\beta$ in CD 4 regulatory T cells and MS patients [24], we further analyzed the expression of TGF- $\beta$ on PBMCs of all study subjects. As shown in Fig. $2 A$, the expression of TGF- $\beta$ was significantly lower in MS patients than healthy controls $(p=0.002)$. TGF- $\beta$ expression was significantly lower in those patients who received rituximab compared to healthy controls $(p=0.01)$ although the difference between 2 groups of patients did not reach statistically significant ( $p$ $0.05)$ (Fig. 2B). TGF- $\beta$ expression was also significantly lower in patients with high and low EDSS scores compared to healthy controls ( $p=0.001$ and $p=0.004$ respectively) (Fig. 2C). Analyzing data based on MS forms, no significant difference was found in terms of TGF- $\beta$ expression ( $p>0.05$ ) (Fig. 2D).

To determine any plausible correlation between HERV-K18 env expression and TGF- $\beta$, regression linear analysis was applied (Fig. 3). Interestingly, an inverse correlation was found between HERV-K18 env expression and TGF- $\beta$ expression in MS patients $(p=0.04)$. Such a correlation was not observed for healthy controls (Fig. $3 \mathrm{~A}$ and $3 \mathrm{C}$ respectively).

\section{In vitro stimulation of PBMCs with EBV in the presence and the absence of vitamin D. An inverse} correlation has been recently reported between EBV DNA load and serum concentration of vitamin D in MS patients $[9,17]$. Given the fact that EBV has the capability to transactivate HERV-K18 env, we further aimed to evaluate the in vitro effects of EBV infection on HERV-K18 env expression in the presence and the absence of vitamin D on PBMCs. However, we could not find significant differences in treated groups with regards to HERV-K18 env expression ( $p=0.05$; Fig. 4) although EBV infected cells were found to exert different transcriptional patterns in the presence and the absence of vitamin $D$ treatment (Table2).

Table 2

The expression of HERV-K18 env in the stimulation groups.

\begin{tabular}{|lll|}
\hline Stimulation groups & $\begin{array}{l}\text { HERV-K18 env expression in } \\
\text { MS } \\
\text { (Mean } \pm \text { SD) }\end{array}$ & $\begin{array}{l}\text { HERV-K18 env expression in healthy } \\
\text { controls } \\
\text { (Mean } \pm \text { SD) }\end{array}$ \\
\hline PBMC & $1.131 \pm 0.97$ & $1.118 \pm 0.98$ \\
\hline PBMC + vitamin D & $1.075 \pm 0.74$ & $0.974 \pm 0.54$ \\
\hline PBMC + EBV & $1.273 \pm 0.89$ & $0.906 \pm 0.73$ \\
\hline $\begin{array}{l}\text { PBMC + EBV + vitamin } \\
\text { D }\end{array}$ & $0.977 \pm 0.72$ & $1.145 \pm 0.67$ \\
\hline Loading [MathJax]/jax/output/CommonHTML/fonts/TeX/fontdata.js & \\
\hline
\end{tabular}




\section{Discussion:}

Multiple sclerosis is a chronic inflammatory disease of CNS; whose etiology remains poorly defined. In this study, we have shown that 1) the expression of HERV-K18 env is significantly higher in MS patients than healthy controls; 2 ) TGF- $\beta$ expression was significantly lower in MS patients than healthy controls 3 ) a negative correlation was found between the expression of HERV-K18 env and TGF- $\beta$ expression in MS patients but not in healthy controls; and 4) in-vitro EBV infected PBMCs were found to exert different transcriptional patterns of HERV-k18 env after $72 \mathrm{~h}$ in the presence and the absence of vitamin D treatment although the difference did not reach statistically different between treated groups.

While differential expression of HERVs have been reported in certain autoimmune diseases such as MS, their clinical significance is poorly defined. Moreover, it is not clear whether they are indicative of disease inheritance or act as markers of environmental/endogenous stress [25]. There are few studies with regards to the HERV-K family including HERV-K18 env in MS patients [26-28]. In this study, the expression of HERV-K18 env in MS patients was significantly higher than healthy controls as reported previously. Tai et al, have reported HERV-K18 env as a risk factor in MS [29]. Furthermore, a meta-analysis study evaluating the link between HERV-K18 polymorphisms and autoimmune diseases found a significant association between the haplotype HERV-K18.3 (97Y154W) and the American and Spanish MS population with an OR of $1.22(95 \% \mathrm{Cl}: 1.09-1.38)$ [15]. It has been reported that treatment can also impact the expression of HERVs [30]. Indeed, previous reports indicate that patients with pemphigus vulgaris who received rituximab treatment showed a decreased expression of HERV-K (HML-2) env compared to healthy controls [31]. However, in this study we could not find a significant difference when looking at the expression of HERV-K18 env based on rituximab treatment. Rituximab may play a role in decreasing the expression of HERVs through B cell depletion that co-express EBV and HERV proteins [32]. Given the fact that HERVs can be expressed by different cells [33]. It has been shown that the increased DNA copy number of MSRV (HERV-W) in patients with MS can also be influenced by gender and disease severity [34] although we could not find such a difference for HERV-K18 env in this study.

TGF- $\beta$ is thought to play a major role in the development and function of CD4 regulatory T cells in MS patients [24]. In line with our previous finding [5], the expression of TGF- $\beta$ was found to be significantly lower in MS patients compared to healthy controls. It may show the presence of lower frequency of Treg cells in these patients [35] although yet to be documented. Given the association of TGF $\beta 1$ SNPs with a good response to rituximab therapy in patients with rheumatoid arthritis [33] and increased level of TGF- $\beta$ expression following treatment with rituximab in lupus nephritis [36], we further analyzed the expression of TGF- $\beta$ based on rituximab treatment in our study subjects. However, the difference observed between MS patients who received rituximab treatment and other groups was not statistically significant.

This study further aimed to check if there is any association between HERV-K18 env expression with TGF$\beta$. Interestingly, an inverse correlation was observed between HERV-K18 env and TGF- $\beta$ expression. Although our finding supports a potential role of TGF- $\beta$ in HERV-K18 env induction in MS patients, further ctudioc aro warrantod tn dolinoato tho morhanicm chohind the involvement of TGF- $\beta$ and HERVs. While Loading [MathJax]/jax/output/CommonHTML/fonts/TeX/fontdata.js 
studies investigating the plausible association of TGF- $\beta$ and HERVs are scarce particularly in autoimmune diseases, it has been suggested that TGF- $\beta 1$ may play an important role in medicating HERV signaling in breast cancer [37]. Different transcriptional patterns of TGF- $\beta$ with regards to HERVK18 env may also exert complex interactions of different risk factors in MS development. Although yet to be defined, activation of human B cells by EBV [38] and the ability of B cells to negatively regulates TGF- $\beta$ production [39] are the events that may impact HERV-K18 env expression.

It has been previously revealed that some viral agents can activate the expression of HERVs in vitro [17]. Indeed, EBV was shown to induce the super antigenic activity of HERV-K18 env in latently infected cells [18]. In vitro stimulation of PBMCs with EBV for 72 hours did not show statistically significant difference in terms of HERV-K18 env expression although EBV infected cells of MS patients and healthy controls showed opposite patterns in the absence or the presence of vitamin D treatment. Vitamin D appears to exert an effective role on HERV-K18 env expression but apparently difference time points would provide better indication of in-vitro effects of different risk factors in these patients. Further studies with greater number of subjects is necessary to validate the results reported in the current work. Also, additional studies are recommended to investigate the expression level of other HERVs involved MS pathogenesis.

\section{Conclusion}

Our results further highlight the mysterious role of HERV-K18 env in MS pathogenesis. However, the complex interactions of different risk factors with immune system in patients with MS would be imperative and future studies are warranted to delineate the missing links in this scenario.

\section{Abbreviations}

HERVs

Human endogenous retroviruses

MS

multiple sclerosis

PBMCs

peripheral blood mononuclear cells

TGF- $\beta$

Transforming Growth Factor Beta

EBV

Epstein-Barr virus

\section{Declarations}

Acknowledgments 
This work was supported by Tehran University of Medical Sciences [Grant No.: 95-02-27-31949]. All experimental procedures were approved by the local research ethics committee (approval code: IR.TUMS.SPH.REC.1395.756) of the Tehran University of Medical Sciences (TUMS).

\section{Declarations}

Not applicable

\section{References}

Reference

1. Stys PK, Zamponi GW, van Minnen J, Geurts JJ (2012) Will the real multiple sclerosis please stand up? Nature reviews Neuroscience 13:507-514

2. Olsson T, Barcellos LF, Alfredsson L (2016) Interactions between genetic, lifestyle and environmental risk factors for multiple sclerosis. Nature Reviews Neurology 13:25

3. Tarlinton RE, Khaibullin T, Granatov E, Martynova E, Rizvanov A, Khaiboullina S (2019) The Interaction between Viral and Environmental Risk Factors in the Pathogenesis of Multiple Sclerosis. International journal of molecular sciences 20:303

4. Mostafa A, Jalilvand S, Shoja Z, Nejati A, Shahmahmoodi S, Sahraian MA, Marashi SM (2017) Multiple sclerosis-associated retrovirus, Epstein-Barr virus, and vitamin D status in patients with relapsing remitting multiple sclerosis. Journal of medical virology 89:1309-1313

5. Nejati A, Shoja Z, Shahmahmoodi S, Tafakhori A, Mollaei-Kandelous Y, Rezaei F, Hamid KM, Mirshafiey A, Doosti R, Sahraian MA, Mahmoudi M, Shokri F, Emery V, Marashi SM (2016) EBV and vitamin $\mathrm{D}$ status in relapsing-remitting multiple sclerosis patients with a unique cytokine signature. Medical Microbiology Immunology 205:143-154

6. Munger K, Ascherio A (2013) Understanding the joint effects of EBV and vitamin D in MS. Mult Scler 19:1554-1555

7. Decard BF, von Ahsen N, Grunwald T, Streit F, Stroet A, Niggemeier P, Schottstedt V, Riggert J, Gold R, Chan A (2012) Low vitamin D and elevated immunoreactivity against Epstein-Barr virus before first clinical manifestation of multiple sclerosis. Journal of neurology neurosurgery psychiatry 83:11701173

8. Wergeland S, Myhr KM, Loken-Amsrud KI, Beiske AG, Bjerve KS, Hovdal H, Midgard R, Kvistad SS, Holmoy T, Riise T, Torkildsen O (2016) Vitamin D, HLA-DRB1 and Epstein-Barr virus antibody levels in a prospective cohort of multiple sclerosis patients. European journal of neurology 23:1064-1070

9. Mostafa A, Jalilvand S, Shoja Z, Nejati A, Shahmahmoodi S, Sahraian MA, Marashi SM (2017) Multiple sclerosis-associated retrovirus, Epstein-Barr virus, and vitamin D status in patients with relapsing remitting multiple sclerosis. Journal of medical virology 89:1309-1313

10. . 409:860-921 
11. Gröger V, Cynis H (2018) Human Endogenous Retroviruses and Their Putative Role in the Development of Autoimmune Disorders Such as Multiple Sclerosis. Front Microbiol 9:265-

12. Antony JM, Deslauriers AM, Bhat RK, Ellestad KK, Power C (2011) Human endogenous retroviruses and multiple sclerosis: innocent bystanders or disease determinants? Biochimica et biophysica acta 1812:162-176

13. Laska MJ, Brudek T, Nissen KK, Christensen T, Moller-Larsen A, Petersen T, Nexo BA (2012) Expression of HERV-Fc1, a human endogenous retrovirus, is increased in patients with active multiple sclerosis. J Virol 86:3713-3722

14. Nexo BA, Christensen T, Frederiksen J, Moller-Larsen A, Oturai AB, Villesen P, Hansen B, Nissen KK, Laska MJ, Petersen TS, Bonnesen S, Hedemand A, Wu T, Wang X, Zhang X, Brudek T, Maric R, Sondergaard HB, Sellebjerg F, Brusgaard K, Kjeldbjerg AL, Rasmussen HB, Nielsen AL, Nyegaard M, Petersen T, Borglum AD, Pedersen FS (2011) The etiology of multiple sclerosis: genetic evidence for the involvement of the human endogenous retrovirus HERV-Fc1. PloS one 6:e16652

15. de la Hera B, Varade J, Garcia-Montojo M, Lamas JR, de la Encarnacion A, Arroyo R, FernandezGutierrez B, Alvarez-Lafuente R, Urcelay E (2013) Role of the human endogenous retrovirus HERV$\mathrm{K} 18$ in autoimmune disease susceptibility: study in the Spanish population and meta-analysis. PLoS One 8:e62090

16. Hsiao FC, Lin M, Tai A, Chen G, Huber BT (2006) Cutting edge: Epstein-Barr virus transactivates the HERV-K18 superantigen by docking to the human complement receptor 2 (CD21) on primary B cells. Journal of immunology (Baltimore, Md: 1950). 177:2056-60

17. Sutkowski N, Conrad B, Thorley-Lawson DA, Huber BT (2001) Epstein-Barr virus transactivates the human endogenous retrovirus HERV-K18 that encodes a superantigen. Immunity 15:579-589

18. Hsiao FC, Tai AK, Deglon A, Sutkowski N, Longnecker R, Huber BT (2009) EBV LMP-2A employs a novel mechanism to transactivate the HERV-K18 superantigen through its ITAM. Virology 385:261266

19. Chen J, Foroozesh M, Qin Z (2019) Transactivation of human endogenous retroviruses by tumor viruses and their functions in virus-associated malignancies. Oncogenesis 8:6

20. Thompson AJ, Banwell BL, Barkhof F, Carroll WM, Coetzee T, Comi G, Correale J, Fazekas F, Filippi M, Freedman MS (2018) Diagnosis of multiple sclerosis: 2017 revisions of the McDonald criteria. The Lancet Neurology 17:162-173

21. Shokri F, Mageed RA, Maziak BR, Jefferis R (1991) Expression of VHIII-associated cross-reactive idiotype on human B lymphocytes. Association with staphylococcal protein A binding and Staphylococcus aureus Cowan I stimulation. Journal of immunology (Baltimore, Md: 1950). 146:936 $-40$

22. Teymoori-Rad M, Sahraian MA, Mokhtariazad T, Nejati A, Mozdabadi RSK, Amiri MM, Shokri F, Marashi SM (2021) Illuminating the in vitro effects of Epstein-Barr virus and vitamin D on immune response in multiple sclerosis patients. Journal of NeuroVirology 
23. Livak KJ, Schmittgen TD (2001) Analysis of relative gene expression data using real-time quantitative PCR and the 2(-Delta Delta C(T)) Method. Methods (San Diego. Calif) 25:402-408

24. Lee PW, Severin ME, Lovett-Racke AE (2017) TGF- $\beta$ regulation of encephalitogenic and regulatory $T$ cells in multiple sclerosis. Eur $\mathrm{J}$ Immunol 47:446-453

25. Balada E, Vilardell-Tarres M, Ordi-Ros J (2010) Implication of human endogenous retroviruses in the development of autoimmune diseases. International reviews of immunology 29:351-370

26. Rasmussen HB, Geny C, Deforges L, Perron H, Tourtelotte W, Heltberg A, Clausen J (1997) Expression of endogenous retroviruses in blood mononuclear cells and brain tissue from multiple sclerosis patients. Acta neurologica Scandinavica Supplementum 169:38-44

27. Antony JM, Izad M, Bar-Or A, Warren KG, Vodjgani M, Mallet F, Power C (2006) Quantitative analysis of human endogenous retrovirus-W env in neuroinflammatory diseases. AIDS research human retroviruses 22:1253-1259

28. Moyes DL, Martin A, Sawcer S, Temperton N, Worthington J, Griffiths DJ, Venables PJ (2005) The distribution of the endogenous retroviruses HERV-K113 and HERV-K115 in health and disease. Genomics 86:337-341

29. Tai AK, O'Reilly EJ, Alroy KA, Simon KC, Munger KL, Huber BT, Ascherio A (2008) Human endogenous retrovirus-K18 Env as a risk factor in multiple sclerosis. Mult Scler 14:1175-1180

30. Demoor-Fossard M, Galéra P, Santra M, lozzo RV, Pujol J-P, Rédini F (2001) A Composite Element Binding the Vitamin D Receptor and the Retinoic X Receptor a Mediates the Transforming Growth Factor- $\beta$ Inhibition of Decorin Gene Expression in Articular Chondrocytes. Journal of Biological Chemistry 276:36983-36992

31. Karimi A, Esmaili N, Ranjkesh M, Zolfaghari MA (2019) Expression of human endogenous retroviruses in pemphigus vulgaris patients. Molecular biology reports

32. Dreyfus DH (2011) Autoimmune disease: A role for new anti-viral therapies? Autoimmunity reviews 11:88-97

33. Daien Cl, Fabre S, Rittore C, Soler S, Daien V, Tejedor G, Cadart D, Molinari N, Daures JP, Jorgensen C, Touitou I (2012) TGF beta1 polymorphisms are candidate predictors of the clinical response to rituximab in rheumatoid arthritis. Joint, bone, spine: revue du rhumatisme. 79:471-5

34. Garcia-Montojo M, Dominguez-Mozo M, Arias-Leal A, Garcia-Martinez Á, De las Heras V, Casanova I, Faucard R, Gehin N, Madeira A, Arroyo R, Curtin F, Alvarez-Lafuente R, Perron H (2013) The DNA copy number of human endogenous retrovirus-W (MSRV-type) is increased in multiple sclerosis patients and is influenced by gender and disease severity. PloS one 8:e53623-e

35. Kleinewietfeld M, Hafler DA (2014) Regulatory T cells in autoimmune neuroinflammation. Immunological reviews 259:231-244

36. Sfikakis PP, Souliotis VL, Fragiadaki KG, Moutsopoulos HM, Boletis JN, Theofilopoulos AN (2007) Increased expression of the FoxP3 functional marker of regulatory T cells following B cell depletion with rituximab in patients with lupus nephritis. Clinical immunology (Orlando Fla) 123:66-73 
37. Zhou F, Li M, Wei Y, Lin K, Lu Y, Shen J, Johanning GL, Wang-Johanning F (2016) Activation of HERV$\mathrm{K}$ Env protein is essential for tumorigenesis and metastasis of breast cancer cells. Oncotarget 7:84093-84117

38. Mrozek-Gorska P, Buschle A, Pich D, Schwarzmayr T, Fechtner R, Scialdone A, Hammerschmidt W (2019) Epstein-Barr virus reprograms human B lymphocytes immediately in the prelatent phase of infection. Proceedings of the National Academy of Sciences. 116:16046-55

39. Molnarfi N, Bjarnadóttir K, Benkhoucha M, Juillard C, Lalive PH (2017) Activation of human B cells negatively regulates TGF- $\beta 1$ production. $\mathrm{J}$ Neuroinflammation 14:13-

\section{Figures}
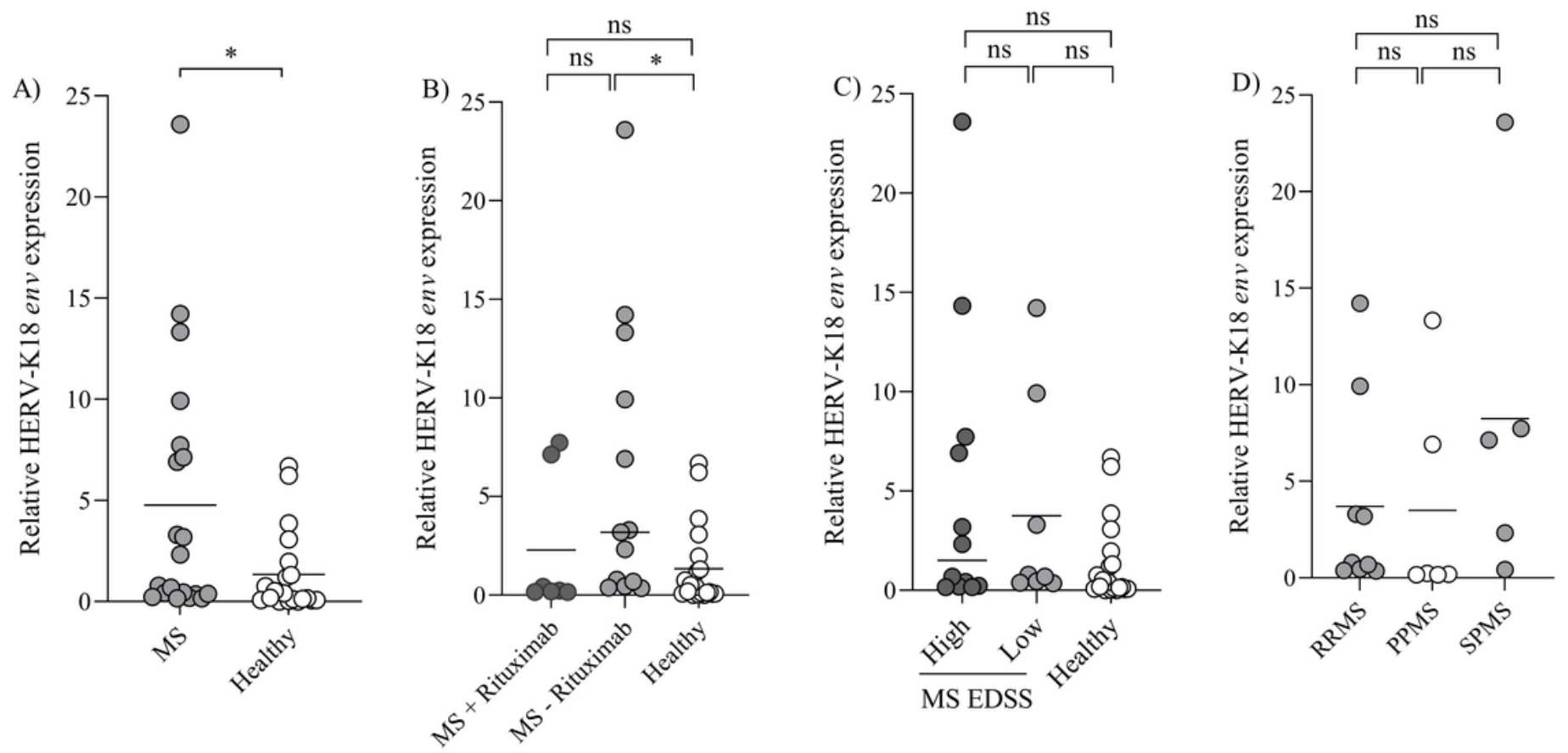

\section{Figure 1}

The expression level of HERV-K18 env. A) The expression level of HERV-K18 env in PBMCs of MS patients compared to healthy controls $(p=0.01)$. Results from MS patients were further subdivided according to treatment with Rituximab, EDSS score, and MS type, respectively (B-D). Data are presented as 2- $\Delta C t$ value. Solid lines indicate mean values and P-value for indicated pairwise comparison was determined using Student's T test analysis. One-way ANOVA comparison test was performed for multiple comparisons. * ${ }^{* *}$, and ns indicate $p$ values $<0.01$, $p$ values $<0.001$, and non-significant, respectively. 


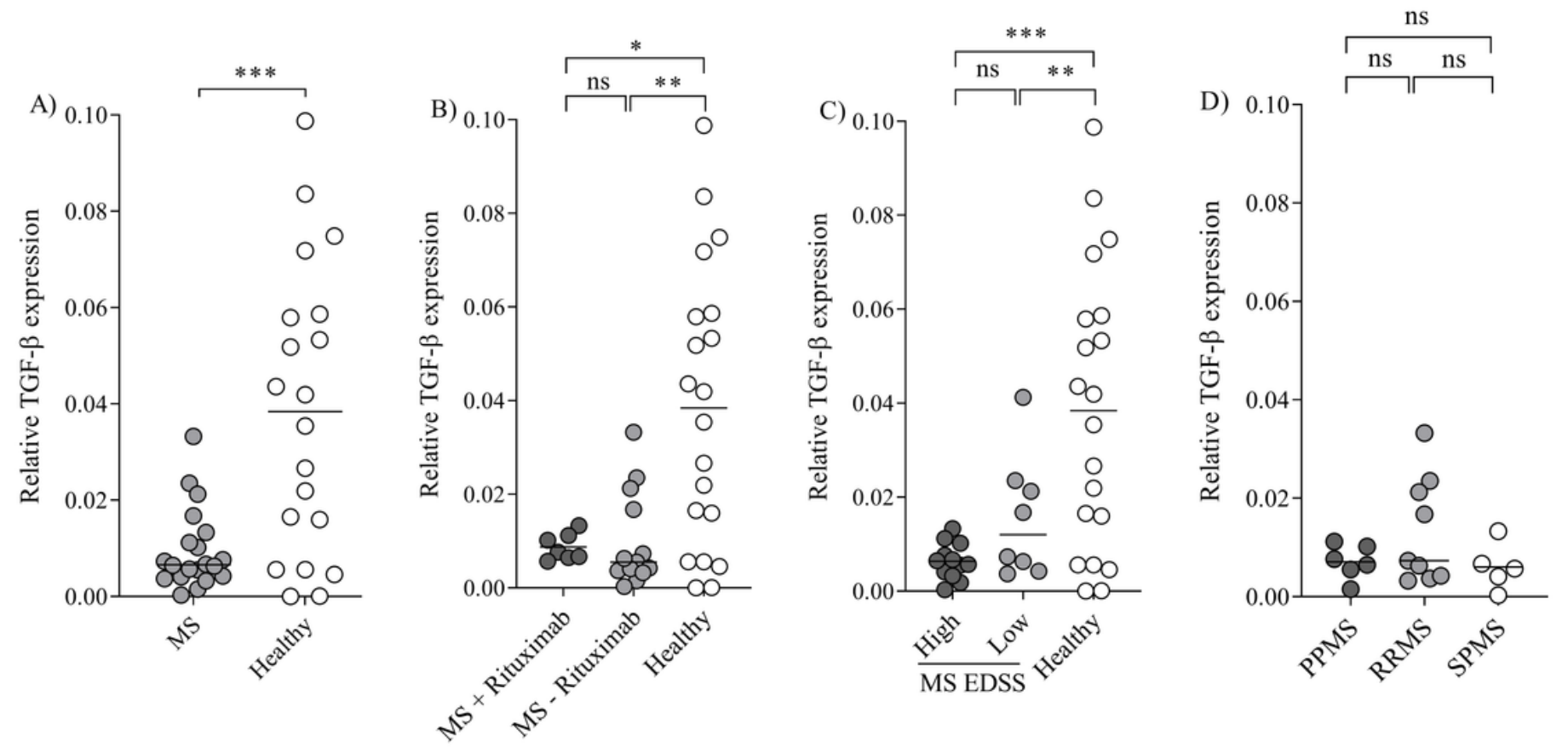

\section{Figure 2}

The expression level of TGF- $\beta$. A) The expression level of TGF- $\beta$ in PBMCs of MS patients compared to healthy controls $(p=0.002)$. Results from MS patients were further subdivided according to treatment with Rituximab, EDSS score, and MS type, respectively (B-D). Data are presented as $2-\Delta C t$ value. Solid lines indicate mean values and P-value for indicated pairwise comparison was determined using Student's T test analysis. One-way ANOVA comparison test was performed for multiple comparisons. *, $\star \star$, and $n s$ indicate $p$ values $<0.01, p$ values $<0.001$, and non-significant, respectively. 


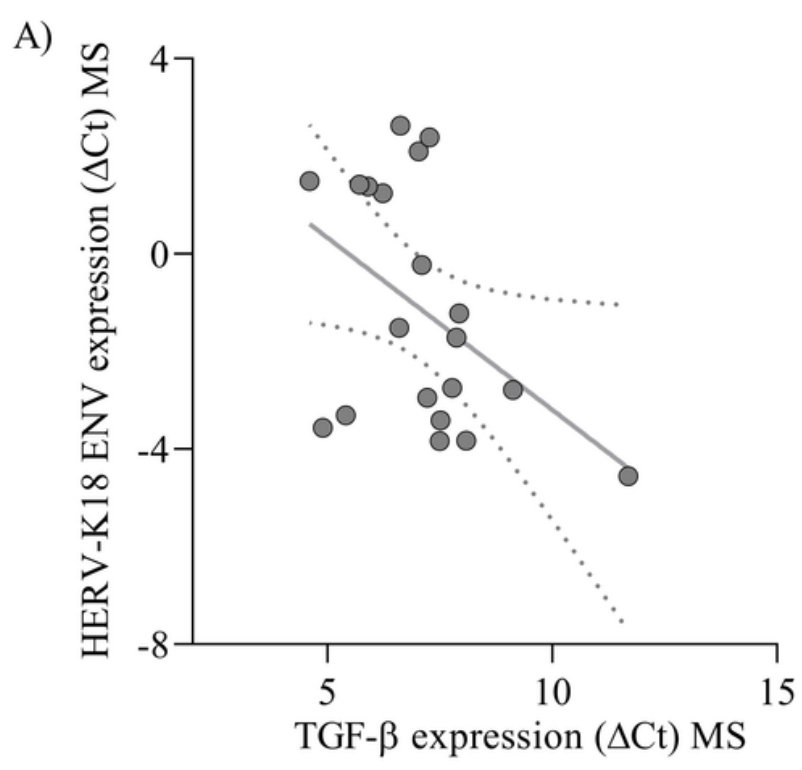

Pvalue $=0.04$ $\mathrm{r}=-0.4$
B)

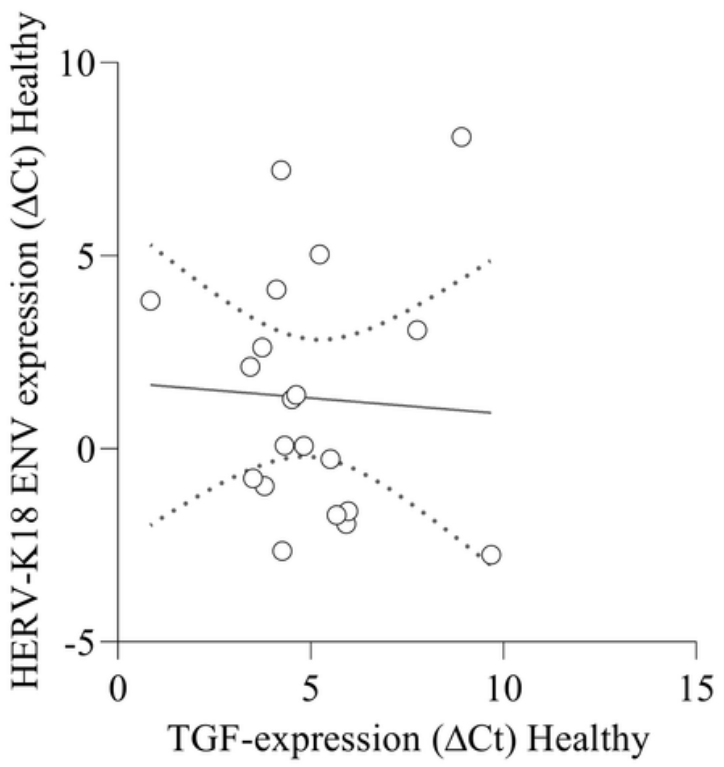

Pvalue $=0.8$ $\mathrm{r}=-0.05$

\section{Figure 3}

Correlation between HERV-K18 env and TGF- $\beta$ expression. A, B) An inverse correlation between HERV-K18 env and TGF- $\beta$ expression in MS patients $(p=0.04, r=-0.4)(p=0.8, r=-0.05)$ but not for healthy controls. Data are presented as $\Delta \mathrm{Ct}$ values. 


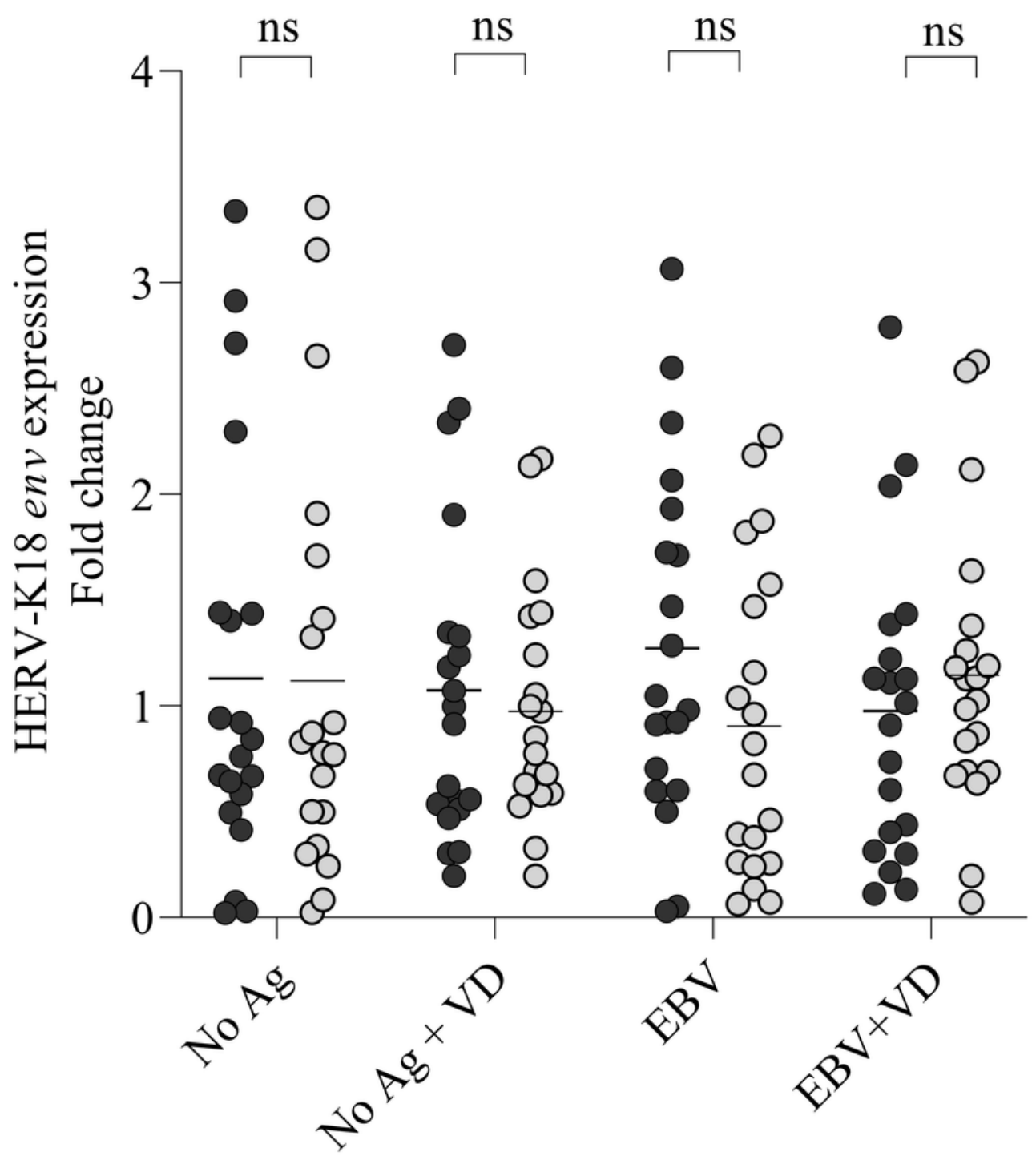

$\begin{array}{ll}- & \text { MS } \\ 0 & \text { Healthy }\end{array}$ $\mathrm{VD}=\operatorname{Vitamin} \mathrm{D}$

Figure 4

The HERV-K18 env expression represented as log10 of fold changes in different stimulating groups with EBV in the presence and the absence of vitamin D in MS patients and healthy controls. ns indicates nonsignificant. $P$ values was determined with repeated measure ANOVA. 